\title{
RISK FACTORS IN PATIENTS WITH TYPE 2 DIABETES MELLITUS
}

\author{
Idalina Diair Regla Carolino ${ }^{1}$ \\ Carlos Alexandre Molena-Fernandes ${ }^{2}$ \\ Raquel Soares Tasca ${ }^{3}$ \\ Sonia Silva Marcon ${ }^{4}$ \\ Roberto Kenji Nakamura Cuman ${ }^{3}$
}

Carolino IDR, Molena-Fernandes CA, Tasca RS, Marcon SS, Cuman RKN. Risk factors in patients with type 2 diabetes mellitus. Rev Latino-am Enfermagem 2008 março-abril; 16(2):238-44.

This study was carried out to evaluate the risk factors of type 2 diabetic patients through sociodemographic data, habits of health, anthropometric and biochemist profiles, assisted at a basic public health care unit in Maringá, Paraná. Sixty-six patients, 56 women aged over than 50 years-old were interviewed. High prevalence factors for cardiovascular risk were observed, such as: overweight and obesity, hypertension, dyslipidemia, sedentariness and inadequate diet. Data suggested the need for multidisciplinary intervention programs in health care units associated to educative programs, adjusted diet intake and regular physical activity for these diabetic patients.

DESCRIPTORS: public health; risk factors; diabetes mellitus, type 2

\section{FACTORES DE RIESGO EN PACIENTES CON DIABETES MELLITUS TIPO 2}

El objetivo de este estudio fue verificar los factores de riesgo de las complicaciones de la diabetes mellitus tipo 2, por medio del levantamiento de datos sociodemográficos, hábitos de salud, perfil antropométrico y bioquímico, de pacientes diabéticos tipo 2 atendidos en una Unidad Básica de Salud en la ciudad de Maringá, Paraná. Fueron entrevistados y evaluados 66 pacientes con más de 50 años; 56 eran del sexo femenino. Se verificó una elevada presencia de factores de riesgo cardiovascular en los pacientes investigados: sobrepeso y obesidad, hipertensión, dislipidemia, sedentarismo y dieta no saludable. Los resultados indican la necesidad de la implantación de programas de intervención multidisciplinares en unidades básicas de la salud asociada a prácticas educativas, estimulando la adopción de una dieta saludable y la práctica de actividad física regular para estos pacientes.

DESCRIPTORES: salud pública; factores de riesgo; diabetes mellitus tipo 2

\section{FATORES DE RISCO EM PACIENTES COM DIABETES MELLITUS TIPO 2}

O objetivo deste estudo foi verificar os fatores de risco das complicações do diabetes mellitus tipo 2, por meio de levantamento de dados sociodemográficos, hábitos de saúde, perfil antropométrico e bioquímico de pacientes diabéticos tipo 2, atendidos em Unidade Básica de Saúde, na cidade de Maringá, Paraná. Foram entrevistados e avaliados 66 pacientes acima de 50 anos, sendo 56 do sexo feminino. Verificou-se elevada prevalência de fatores de risco cardiovascular nos pacientes investigados: sobrepeso e obesidade, hipertensão, dislipidemia, sedentarismo e dieta não saudável. Os resultados indicam a necessidade da implantação de programas de intervenção multidisciplinares em unidades básicas de saúde, associados a práticas educativas, estimulando a adoção de dieta saudável e a prática de atividade física regular para esses pacientes.

DESCRITORES: saúde pública; fatores de risco; diabetes mellitus tipo 2

${ }^{1}$ Nutritionist, Master's student, Maringá State University, Brazil, e-mail: idrcarolino@uem.br; ${ }^{2}$ Physical Education Faculty, M.Sc. in Health Sciences, Faculty of CESUMAR, e-mail: carlos_alexandre@cesumar.br; ${ }^{3} \mathrm{PhD}$, Pharmacist, e-mail: rkncuman@uem.br; ${ }^{4}$ PhD, RN, e-mail: ssmarcon@uem.br. Maringá State University, Brazil 


\section{INTRODUCTION}

$\boldsymbol{T}_{\text {ype }} 2$ diabetes mellitus (DM2) is a chronic and frequent disease, whose prevalence has rapidly and continuously increased around the world in the last decades, acquiring epidemic characteristics in several countries, especially in developing countries. According to the Pan-American Health Organization (PAHO), there is an epidemic in course. In 1985, there were 30 million patients in the world; in 2000, 177 million cases were notified, a number that might increase to 370 million in $2030^{(2)}$.

According to a multi-centric study on the Prevalence of Diabetes in Brazil, carried out in 1988, $7.6 \%$ of the adult population presents this health problem. In 2001, by the time of the National Campaign to Detect Suspect Cases of Diabetes in Brazil, when 20.7 million capillary glycemia tests were performed, $14.6 \%$ of suspicious exams were detected $^{(3)}$. In addition, official morbidity statistics appoint that DM2 is the fifth indication of hospitalization in Brazil and figures among the ten top causes of mortality in the country ${ }^{(4)}$.

In view of these results, the great concern is how to face this situation in the different segments of society. Demographic aging and altered life styles are appointed as the main determinants of the sharp increase in the frequency of DM2 in the last years. Evidence regarding changes in life style, such as nonhealthy eating habits and the lack of regular physical activities, associated to increased life expectancy in Brazil, have been indicated as factors responsible for the increased prevalence of DM2 in the country ${ }^{(5-6)}$.

A recent report by the World Health Organization indicates an association between weight gain, abdominal obesity, sedentariness and the development of DM2, stressing eating habits as one of the main modifiable factors related to the development of non-transmissible chronic diseases ${ }^{(1)}$.

A systematic literature review reveals that, although the influence of the genetic load in the development of the disease is arguable, prevention or retardation of its development among individuals who possess risk factors represents a relevant impact in the population's quality of life, besides the reduction of costs in public health care, caused by complications due the evolution of the disease ${ }^{(5)}$.

In this sense, some studies have demonstrated that the control of weight, diet and increased physical activity diminishes resistance to insulin and consequently, the chances of developing $\mathrm{DM}_{2}{ }^{(7)}$. Additionally, data from PAHO show this is a more efficient measure than the use of medication in primary DM2 prevention ${ }^{(1)}$.

On the other hand, prospective studies, carried out in the United Kingdom (UKPDS) $)^{(8)}$, with type 2 and type 1 diabetes patients (DCCT) ${ }^{(9)}$, clearly show an association between hyperglycemia and the development of DM2 complications, also indicating that the treatment that reduces hyperglycemia, also reduces the risks of diabetic retinopathy, nephropathy and neuropathy.

Therefore, the reduction of modifiable risk factors such as weight, food consumption and physical activity showed significant potential to reduce the risk of developing DM2, even in individuals with a family history ${ }^{(10)}$.

DM2 exerts great economic impact on nations. The cost by diabetic patient is mainly related to a high frequency of acute and chronic complications, which are causes of hospitalizations, disabilities, smaller labor productivity and premature death. In fact, an increasing number of hospitalizations has been observed in Brazil due to DM2 or associated diseases, proportionally higher than hospitalizations due to other causes $^{(4)}$. Reducing the impact of DM2 mainly means reducing the incidence of the disease, foreseeing its occurrence with preventive measures. However, too little is known about health conditions of Brazilians in cities of medium and small size.

Intervention studies on the prevention of diabetes in adult populations suggest that these programs are viable at basic health units ${ }^{(5)}$ and enhance the population's health. There is evidence that, the earlier interventions occur, the more successful the modifications made in life style will be. Thus, studies that evaluate the profile of health service users can help in the prevention of diseases and lasting effects of DM2.

In this context, this study aimed to verify the risk factors of DM2 complications in patients using the Integrated Health Center (NIS II) Mandacaru, Maringá - Paraná, Brazil.

\section{CASES AND METHODS}

A descriptive and cross-sectional study was carried out at the Integrated Health Center NIS - II - Mandacaru, Maringá - PR, Brazil. Data collection 
was carried out in June and July, 2004. From a total of 200 subjects with DM2 registered at this Basic Health Unit, 66 patients were selected (10 males and 56 females) older than 50 years and with a diagnosis of DM2 established for five years or more. Patients were included by nurses from the Family Health Program.

A structured questionnaire was applied and addressed: a) patients' demographic and socioeconomic characteristics: age, gender, schooling, occupation and per capita income; b) eating habits: habitual diet record; c) physical activity: frequency and duration; d) clinical characteristics: pathological antecedents and personal clinical history; e) presence of habits harmful to health: use of tobacco and alcoholism; f) nutritional state and anthropometrical evaluation and, g) use of medication: frequency, quantity and type of medication.

The interviews were carried out by a team previously trained, composed by college graduated interviewers with previous experience in field work. The anthropometrical measures (weight, height and waist and hip circumferences) were performed twice and arithmetic means were computed from the obtained values.

In order to evaluate the nutritional state (overweight and obesity), patients were classified according to the obtained BMI, according to the World Health Organization's (WHO) recommendations, which define: under weight (BMI $\left.<18.5 \mathrm{Kg} / \mathrm{m}^{2}\right)$, normal weight (BMI between 18.5 and $24.9 \mathrm{Kg} / \mathrm{m}^{2}$ ), overweight (BMI between 25 and $29.9 \mathrm{Kg} / \mathrm{m}^{2}$ ) and obesity (BMI $\left.>30 \mathrm{Kg} / \mathrm{m}^{2}\right)^{(1)}$.

The definition of central distribution of adiposity was based on waist and hip ratios (WHR), using threshold values of $\geq 0.85$ and $\geq 0.95$ for women and men, respectively. To characterize arterial hypertension, reference values according to recommendations by the Joint National Committee VII (JVC VII) ${ }^{(11)}$ were used, in which the levels $\geq 90 \mathrm{mmHg}$ for diastolic and $\geq 140 \mathrm{mmHg}$ for systolic indicate arterial hypertension. Patients who presented arterial blood pressure below these levels but reported the use of anti-hypertensive drugs were also considered hypertensive.

In order to characterize eating habits, a direct investigation of food consumption was performed through a 24-hour record, which is considered the ideal strategy to characterize diabetic patterns. Nonhealthy diet was considered as low ingestion of fruits, fibers, greens and vegetables (less than two portions a day); and an elevated ingestion of saturated/trans fat with frequent use of fried food (more than four times a week), simple carbohydrates and sodium, soft drinks and processed foods ${ }^{(1)}$.

All patients who informed non-participation in any kind of physical activity or performed physical activity for less than 20 minutes a day and less than three times a week were considered sedentary.

From the study population, 40 patients attended the Basic Health Unit to perform biochemical exams (lipid and glycemic profile), after fasting for 12 hours. Those individuals presenting seric levels of triglycerides and/or total cholesterol $>200 \mathrm{mg} / \mathrm{dl}$, seric $\mathrm{HDL}$-cholesterol < 45mg/dl, seric LDL-cholesterol > $100 \mathrm{mg} / \mathrm{dl}$ and triglycerides $>150 \mathrm{mg} / \mathrm{dl}^{(12)}$ were considered dyslipidemic.

The medication used by the patients was classified in pharmacological classes according to the Anatomical-Therapeutical-Chemical Classification System (ATC) ${ }^{(13)}$. In this classification, medication is categorized in different groups according to the organ or system they act in and by their chemical, therapeutic and pharmacological properties.

The results obtained were submitted to statistical analysis, using Epi-Info software (version 6.0). Data are presented in frequency and percentage form for qualitative variables and means and standard errors for continuous variables.

This study was approved by the Committee for Ethical Research with Human Beings of Maringá State University (report No 178/2004). Alphabetized participants signed the free and informed consent term, while illiterate participants were verbally clarified by the researchers about all study procedures, informing their consent through digital impression, according to the recommendations by the National Health Council, Resolution no 196/96.

\section{RESULTS AND DISCUSSION}

This study evaluated 66 patients with DM2 followed by the Family Health Program (FHP) in Maringá, Paraná, Brazil. The demographic and socioeconomic characteristics of the patients studied indicate that the great majority is married $(74.24 \%)$ and female $(84.85 \%)$. Although these are very high numbers, they are in agreement with figures by the Health Ministry, that is, incidence and prevalence of 
DM2 1.4 to 1.8 times more higher in women ${ }^{(14)}$. Additionally, women's systematic and continuous search for health care has been suggested to be one of the factors responsible for the predominance of the female gender in health services. Women, in comparison to men, usually take better care of themselves and are historically responsible for medical care of their families. Thus, they are more attentive to disease symptoms and generally seek help early. This is probably associated to the greater supply of health programs specific for the female gender.

There was only one patient older than 80 years, while the age range with the highest concentration of individuals was from 60 to 69 years old $(51.51 \%)$, followed by 50 to 59 years $(30.30 \%)$ and 70 to 79 years $(16.67 \%)$. These findings are coherent with those found in other studies carried out with samples originating from health services ${ }^{(15)}$. Such evidence can be justified by the fact that a higher frequency of DM2 occurs at approximately 60 years of age, and also that Brazilian people tend to seek medical care only at an advanced age.

The patients presented a low education level, $37.88 \%$ were illiterate, $30.30 \%$ studied until the fourth grade, $16.67 \%$ finished primary school and only $12.12 \%$ and $3.03 \%$ attended high school and college, respectively. Data obtained in Brazil in the last IBGE Census $(2000)^{(16)}$ revealed that $86.06 \%$ of the population in Maringá has been alphabetized. Among the patients in this study, $62.12 \%$ were alphabetized, which is lower than the city's mean level. However, it is important to stress that the population in this study is mostly composed of old people, and that most of the elderly have little formal education. In fact, in Brazil, the age range with the lowest alphabetization rates is over 60 years of age. When considering the country's old people in general, one has to bear in mind they come from a time when access to education was difficult.

Regarding per capita income, only one subject received more than three minimum salaries and 47 (71.22\%) gain less than a minimum wage per month, indicating low purchasing power. The largest concentration of the population in Maringá receives between three and 20 minimum wages per month ${ }^{(16)}$. This can be justified by the fact this is a mostly retired population (90.90\%) with a low education level. For the Brazilian population, low education level is generally associated to poor socioeconomic conditions.
The prevalence of cardiovascular risk factors in the patients studied can be observed in Table 1. A great part $(86.36 \%)$ of patients reported family antecedents of some type of chronic disease such as: DM2, hypertension, dislipedemia or coronariopathy.

Table 1 - Prevalence of risk factors in type 2 diabetes patients attended at the Basic Health Unit NIS - II Mandacaru, Maringá, PR, 2004

\begin{tabular}{lcc}
\hline \multicolumn{1}{c}{ Risk Factors } & Frequency & $\%$ \\
\hline Family History & 57 & 86.36 \\
Visceral Obesity $(\mathrm{WHR})$ & 59 & 89.39 \\
Overweight $\left(\mathrm{BMI} \geq 25 \mathrm{Kg} / \mathrm{m}^{2}\right)$ & 33 & 44 \\
Obesity $\left(\mathrm{BMI} \geq 30 \mathrm{Kg} / \mathrm{m}^{2}\right)$ & 28 & 37.33 \\
Sedentariness & 44 & 66.66 \\
Non-healthy diet & 46 & 69.69 \\
Smoking & 3 & 4.54 \\
Alcoholism & 7 & 10.61 \\
Arterial Hypertension & 44 & 66.66 \\
Dyslipidemias & 29 & 72.5 \\
Impaired fasting glycemia $>110 \mathrm{mg} / \mathrm{dl}$ & 11 & 27.50 \\
\hline
\end{tabular}

Regarding the adoption of habits harmful to health, the use of alcohol was more frequent than tobacco. The frequency of these habits is much lower than findings from a recent survey carried out with a diabetic population (22 and 36.1\%, respectively) ${ }^{(15)}$. The values presented in the present study can be due to omission of this information at the moment of the interview, and also to the fact that the majority of the informants are elderly and female.

Regarding the anthropometrical variables, as observed in Table 1, the BMI values obtained appoint excessive weight in most patients (81.33\%), 44\% due to overweight and $37.33 \%$ to obesity, while $89.39 \%$ also present inadequate WHR. These results are similar to those found in a multi-centric study carried out with more than 2,500 DM2patients in 12 cities of different Brazilian regions ${ }^{(3)}$. The high prevalence of overweight diabetic patients has been appointed by epidemiological research, estimating that between 80 and $90 \%$ of individuals with DM2 are obese or overweight ${ }^{(5)}$. The prevalence of obesity in diabetic patients is three times higher than in the population in general, highlighting that higher prevalence of obesity is observed in patients in the South and Southeast ${ }^{(3)}$.

However, despite awareness about the importance of excessive body weight for morbidity and mortality of patients with DM2, the control of this 
variable in diabetic populations has rarely been emphasized in most studies. In addition, the approach to this problem in basic health care has been neglected, since recommendations on the control of these variables exist in most services, but are not accompanied by resources that can adequately support individuals in an effective change that results in weight loss.

In the present study, $66.66 \%$ of patients were classified as hypertensive. A recent study showed that prevalence of hypertension varied between $15 \%$ and $47.8 \%$ in the South of Brazil $^{(17)}$. It is important to highlight that, among diabetic individuals, hypertension is twice more frequent when compared to the population in general and is present in about $50 \%$ of these patients at the moment of diagnosis. A study carried out in Rio Grande do Sul, Brazil, among type 2 diabetes patients, identified a prevalence of hypertension lower than that found in this study ${ }^{(17)}$. This result can be justified by the older age of the participants in this study and also by the high prevalence of overweight and obesity.

Laboratory data indicate high prevalence of dyslipidemias $(72.5 \%)$ in the patients evaluated, similar to that found in a survey with DM2 patients, performed in Rio Grande do Sul: 67\% presented total cholesterol over $200 \mathrm{mg} / \mathrm{dL} ; 65 \%$ triglycerides > 150 $\mathrm{mg} / \mathrm{dL}$ and $47 \%$ low HDL cholesterol ${ }^{(15)}$. It is known that the two main components of diabetic dyslipidemia are the elevated levels of triglycerides and the low levels of HDL-cholesterol, both considered the main predictors of cardiovascular diseases.

The mean values of triglycerides and LDL cholesterol, observed in Table 2, were above those recommended by the American Diabetes Association $(A D A)^{(12)}$. ADA recommends, for diabetic patients, that $\mathrm{HDL}$ cholesterol values must be higher than $45 \mathrm{mg} /$ $\mathrm{dL}$; however, in this study, mean HDL was below this level $(43.48 \mathrm{mg} / \mathrm{dL})$. This study also presented mean values of LDL-cholesterol above recommendations $(133.66 \mathrm{mg} / \mathrm{dL})$ in the patients evaluated.

Such lipid profile, accompanied by the use of medication, strongly suggests inadequate diet and lack of physical activity. However, the need for a better control of lipid levels has to be considered, through a more effective and safe follow-up of the medications in use, which can even require dosage alteration, as well as the association of hypolipemiants $^{(18)}$.
Table 2 - Biochemical and anthropometrical characteristics of patients with type 2 diabetes attended at the NIS - II Mandacaru, Maringá, PR, 2004

\begin{tabular}{lc}
\hline \multicolumn{1}{c}{ Variable } & Mean \pm SE \\
\hline BMl $\left(\mathrm{Kg} / \mathrm{m}^{2}\right)$ & $29.1 \pm 5.24$ \\
WHR & $0.95 \pm 0.08$ \\
Total cholesterol $(\mathrm{mg} / \mathrm{dl})$ & $213.78 \pm 37.16$ \\
$\mathrm{LDL}-$ cholesterol $(\mathrm{mg} / \mathrm{dl})$ & $133.66 \pm 31.44$ \\
$\mathrm{HDL}-$ cholesterol $(\mathrm{mg} / \mathrm{dl})$ & $43.48 \pm 14.54$ \\
VLDL-cholesterol $(\mathrm{mg} / \mathrm{dl})$ & $35.57 \pm 31.72$ \\
Triglycerides $(\mathrm{mg} / \mathrm{dl})$ & $174.20 \pm 87.41$ \\
Fasting glycemia $(\mathrm{mg} / \mathrm{dl})$ & $117.87 \pm 33.20$ \\
\hline
\end{tabular}

$\mathrm{SE}=$ Standard Error

Regarding alteration in the lipid profile, the unfavorable impact of dislipidemia on cardiovascular morbidity and mortality are largely acknowledged, as well as the frequent association of these conditions with diabetes ${ }^{(17)}$. Moreover, a significant increase occurs in morbidity of individuals with types 1 and 2 diabetes mellitus in the presence of dyslipidemias. On the other hand, there is plenty of evidence that the treatment of dislipidemia has a favorable effect on the control of macro vascular disease in diabetic individuals.

It is important to highlight that a high number of individuals $(72.5 \%)$ with acceptable levels of fasting glycemia was observed in this study, a fact that is justifiable by the use of medication. As observed in Table 3, all patients used anti-diabetic drugs, $65.15 \%$ oral hypoglycemiants and $34.85 \%$ insulin.

Table 3 - Prescribed medication used by patients with type 2 diabetes attended at the Basic Health Unit NIS - II Mandacaru, Maringá, PR, 2004

\begin{tabular}{ccc}
\hline Pharmacological Classes (ATC) & Frequency & $\%$ \\
\hline Cardiovascular medication & 44 & 66.66 \\
Diuretics & 25 & 37.87 \\
Hypoglycemiants & 8 & 12.12 \\
Antihypertensive & 12 & 18.18 \\
Central Nervous System Medications & 36 & 54.54 \\
Analgesics & 28 & 42.42 \\
Others & 8 & 12.12 \\
Gastrointestinal Tract and Metabolism Medications & 66 & 100 \\
Anti diabetics & 66 & 100 \\
Others & 21 & 31.82 \\
\hline
\end{tabular}

However, these patients did not present adequate control of other parameters such as: arterial pressure and seric levels of lipids, which are relevant to diminish the risk of macrovascular complications of diabetes, responsible for $65 \%$ of mortality causes in this population ${ }^{(17)}$. In fact, according to $\operatorname{ADA}^{(12)}$, antihypertensive and antidyslipidemic treatments are 
extremely important for diabetic patients and reduce morbidity and mortality in this population. In this context, pharmacological measures associated to changes in life style are essential in the initial treatment of the diabetic patient ${ }^{(12)}$. In this study, it was observed that only $18.18 \%$ and $12.12 \%$ of patients used antihypertensive and hypolipemiants, respectively. In addition, the lack of regular physical activity (66.66\%) and non-healthy diet (69.69\%) were observed in a high number of patients.

According to ADA recommendations, therapeutic intervention through regular physical exercise and a healthy diet is essential during the patient's follow-up, towards the prevention and control of cardiovascular diseases ${ }^{(12)}$. In this study, a higher prevalence of sedentary patients and non-healthy eating habits was observed. Thus, changes in life style, controlled diet and regular physical activity are important for the reduction of risk factors in these patients.

Regarding non-healthy diets, parameters of consumption of saturated/trans fat, sodium and simple carbohydrates were considered for this evaluation. Known as "western diet", this diet is characterized by a high ingestion of red meat, integral dairy products, sweetened drinks, sugar and desserts, with reduced consumption of fruits, greens and vegetables, which is directly related to the risk of developing and/or causing micro and macro vascular complications of diabetes $^{(15)}$.

\section{FINAL CONSIDERATIONS}

The characterization of patients in this study, attended at a basic health unit in Maringá - Paraná,
Brazil showed high prevalence of risk factors concomitant with DM2. These results appoint that the reduction of body weight, control of arterial hypertension and dyslipedimia must be considered in the treatment of DM2 patients at basic health units, especially adopting conservative measures, such as healthy diet and regular physical activity. The Brazilian Single Health System and health professionals must be capable and motivated to perform the interventions needed to improve the population's quality of life, working towards the reduction of risk factors and, consequently, of non-transmissible chronic diseases.

More epidemiological studies on the profile of DM2patients are important in Brazil, so that more efficacious interventions can be planned, especially at the regional level.

The organization and systematization of services for specific population groups, based on the population's epidemiological profile, are difficult because of generalized population indicators. In the case of care delivery by the public service, which is based on spontaneous demand, this does not always reflect the needs of the population, for instance, for diabetic and/or hypertensive people attended at Basic Health Units (UBS) in Maringá.

Therefore, the use of information is essential and strategic in the health area in order to support plans and projects administered by the city management. The adoption of preventive and therapeutic measures regarding risk factors in type 2 diabetes is an emergent need in primary health care of this city. The implementation of multidisciplinary programs at all care levels for diabetic patients and epidemiological studies on the profile and characterization of individuals must be promoted, so that more effective interventions can be planned.

\section{REFERENCES}

1. World Health Organization. WHO/FAO Expert Consultation. Diet, nutricion and the prevention of chronic diseases. Genebra: World Hearth Organization/Food and Agriculture Organization; 2003.

2. Wild S, Roglic G, Green A, Sicree S, King H. Global prevalence of diabetes - Estmates for the year 2000 and projections for 2030. Diabetes Care 2004; 27:1047-50.

3. Gomes MB, Neto DG, Mendonça E, Tambascia MA, Fonseca RM, Réa RR. Prevalência de sobrepeso e obesidade em pacientes com diabetes mellitus do tipo 2 no Brasil: estudo multicêntrico nacional. Arq Bras Endocrinol Metab 2006; 50(1): 136-44.
4. DATASUS [homepage na Internet]. Brasília: Ministério de Saúde. [acesso em 2007 novembro]. Informações de Saúde. Disponível em: http://tabnet.datasus.gov.br/tabnet/ tabnet.htm\# Morbidade.

5. Sartorelli DS, Franco LJ, Cardoso MA. Intervenção nutricional e prevenção primária do diabetes mellitus tipo 2: uma revisão sistemática. Cad. Saúde Pública 2006; 22(1):7-18.

6. Ortiz MCA, Zanetti ML. Diabetes Mellitus: fatores de risco em uma instituição de ensino na área da saúde. Rev LatinoAm Enfermagem 2000; 8 (06):128-32.

7. Tuomilehto J, Lindstrom J, Eriksson JG, Valle TT, Hamalainen $\mathrm{H}$, Ilanne-Parikka $\mathrm{P}$ et al. Prevention of type 2 diabetes by changes in lifestyle among subjects with impaired glucose tolerance. N Engl J Med 2001; 344:1343-50. 
8. American Diabetes Association. Implications of the United Kingdom prospective diabetes study. Diabetes Care 2003; 26(suppl 1):S28-S32.

9. Diabetes Control and Complications Trial Research Group: The effect of intensive treatment of diabetes on the development and progression of long-term complications in insulin-dependent diabetes mellitus. N Engl J Med 1993; 329: $977-86$.

10. Lyra R, Oliveira M, Lins D, Cavalcanti N. Prevenção do Diabetes Mellitus tipo 2. Arq Bras Endocrinol Metab 2006; 50(2):239-49.

11. Chobanian AV, Bakris GL, Black, HR. The Seventh Report of the Joint National Committee on Prevention, Detection, Evaluation and Treatment of High Blood Pressure. Hipertension 2003; 42:1206-52.

12. American Diabetes Association Standards of Medical Care in Diabetes. American Diabetes Association: Clinical Practice Recommendations 2004: Position Statement. Diabetes Care 2004; 27(suppl 1):15-35.

13. World Health Organization. Collaborating Centre for Drug Statistics Methodology. Anatomical Therapeutic Chemical (ATC) classification index with Defined Daily Doses (DDD's). Oslo: WHO Collaborating Centre for Drug Statistics Methodology; 2000.

14. Ministério da Saúde. Organização Pan-Americana da Saúde. Avaliação do plano de reorganização da atenção à hipertensão arterial e ao diabetes mellitus no Brasil. Brasília: Ministério da Saúde, 2004.

15. Scheffel RS, Bortolanza D, Weber CS, Costa WLA, Canani LH, Santos KG et al. Prevalência de complicações micro e macrovasculares e de seus fatores de risco em pacientes com Diabetes Melito do tipo 2 em atendimento ambulatorial. Rev Assoc Med Bras 2004; 50(3): 263-7.

16. Instituto Brasileiro de Geografia e Estatistica. Censo Demografico 2000. Características da população e dos domicílios resultados do universo. Brasília: IBGE, 2000.

17. Gus I, Fischmann A, Medina C. Prevalence of risk factors for coronary artery disease in the Brazilian State of Rio Grande do Sul. Arq Bras Cardiol 2002; 78(5):484-90.

18. Moreira RO, Santos RD, Martinez L, Saldanha FC, Pimenta JLAC, Feijoo J, Jahnke N, Mangile OC, Kupfer R. Perfil lipídico de pacientes com alto risco para eventos cardiovasculares na prática clínica diária. Arq Bras Endocrinol Metab 2006; 50(3):481-89. 